\title{
Use of BIOME-BGC to simulate water and carbon fluxes within Mediterranean macchia
}

\author{
Marta Chiesi ${ }^{(1)}$, Gherardo Chirici ${ }^{(2)}$, Piermaria Corona ${ }^{(3)}$, Pierpaolo \\ Duce $^{(4)}$, Riccardo Salvati ${ }^{(3)}$, Donatella Spano ${ }^{(5)}$, Francesco P. Vaccari ${ }^{(1)}$, \\ Fabio Maselli ${ }^{(1)}$
}

The biogeochemical model BIOME-BGC is capable to estimate the main ecophysiological processes characterising all terrestrial ecosystems. To this aim it needs to be properly adapted to reproduce the behaviour of each biome type through a calibration phase. The aim of this paper is to adapt BIOME-BGC to reproduce the evapotranspiration (ET) and photosynthesis (GPP) of Mediterranean macchia spread all over Italy. Ten different sites were selected in the Centre-South of Italy and their gross primary production (GPP) was estimated by applying a parametric model, C-Fix, based on remotely sensed data for ten years (1999-2008). These monthly data were then used to calibrate BIOME-BGC through an iterative process which led to reproduce the spatial and temporal GPP variations found by C-Fix. The calibrated model was then applied to simulate the ET and GPP of two Italian sites characterised by the presence of an eddy flux tower; its performances were evaluated against ground data by common statistics. The results obtained indicate that, after a proper calibration phase, BIOME-BGC can be applied to estimate the evapotranspiration and photosynthesis of Mediterranean macchia with a good accuracy, strictly dependent on the input data utilised.

Keywords: Evapotranspiration, Gross primary production, C-Fix, E-OBS dataset

\section{Introduction}

One of the most important research themes in global ecology is related to the study of water and carbon fluxes within terrestrial ecosystems. This is fundamental to understand the effects of global change on vegeta-

$\square$ (1) IBIMET-CNR, via Madonna del Piano 10, 50019 Sesto Fiorentino (FI - Italy); (2) EcoGeoFor - Università del Molise, Contrada Fonte Lappone snc, 86090 Pesche (IS Italy); (3) DISAFRI - Università della Tuscia, v. S. Camillo Lellis snc, I-01100 Viterbo (VT Italy); (4) IBIMET-CNR, Traversa la Crucca 3, Regione Baldinca, I-07100 Li Punti (SS Italy); (5) Università degli Studi di Sassari, Dipartimento di Economia e Sistemi Arborei (DESA), Euro Mediterranean Center on Climate Change - CMCC, via De Nicola 9, I07100 Sassari (Italy).

@,Marta Chiesi (m.chiesi@ibimet.cnr.it)

Received: Dec 05, 2011 - Accepted: Feb 01, 2012

Citation: Chiesi M, Chirici G, Corona P, Duce $P$, Salvati R, Spano D, Vaccari FP, Maselli $F$, 2012. Use of BIOME-BGC to simulate water and carbon fluxes within Mediterranean macchia. iForest 5: 38-43 [online 2012-0430] URL: http://www.sisef.it/

iforest/contents/?id=ifor0605-009

Communicated by: Roberto Tognetti tion and consequently apply sustainable management practices (Waring \& Running 2007). Several studies have been carried out on this subject concerning in particular forest ecosystems (e.g., Cramer et al. 1999, Yang et al. 2007).

As reported by IPCC (2007), quantifying the amount of forest carbon pools and their variation during time is of fundamental importance in the Mediterranean area, which is one of the most vulnerable to global change. Mediterranean macchia is a particular biome type which is spread all around the Mediterranean basin. In Italy it covers wide areas in the centre and in the south and is therefore a potential carbon sink, but little is known about its capacity to store carbon. These areas are potentially characterised by consistent changes in time; the surface covered by macchia is supposed to increase as a response to land abandonment and, in some cases, forest degradation and to decrease when evolving towards different forest types in successional ecosystems trends (ISPRA 2010).

To quantify the water and carbon fluxes within terrestrial ecosystems on a regional scale, the most common approach is based on the use of models of ecosystem processes, often integrated with remotely sensed data (e.g., Matsushita \& Tamura 2002, Corona 2010). Among these simulation models, BIOME-BGC was largely applied to simu- late the behaviour of different forest types for monitoring and predicting purposes (e.g., Chiesi et al. 2010). In general, this model was chosen for its suitability to provide information on water, carbon and nitrogen cycles within forest and non-forest ecosystems and for its relative simplicity in reproducing vegetation processes based on biometypes (Running \& Hunt 1993, White et al. 2000).

So far, BIOME-BGC has never been applied to simulate the behaviour of Mediterranean macchia. Therefore, its operational application for estimating the water and carbon fluxes of macchia requires a preliminary calibration procedure to adapt the model to this new biome type. Following Chiesi et al. (2007), this operation can be carried out using monthly photosynthesis (GPP) estimates derived from an NDVI-based parametric model (Modified C-Fix), which was recently demonstrated to accurately depict productivity features of existing Italian forests (Veroustraete et al. 2002, Maselli et al. 2009).

The current paper aims at adapting BIOME-BGC to simulate the main processes of Mediterranean macchia. The paper first describes the study areas and data considered. Next, the properties of BIOME-BGC are briefly introduced together with the data processing steps applied. In particular this section is divided into:

1. the calibration phase, conducted with the objective of identifying the optimal model configuration for Mediterranean macchia;

2. the validation phase, consisting in applying the original and the calibrated versions of BIOME-BGC in two additional sites for which independent data of evapotranspiration (ET) and GPP exist. These are used to test the accuracy of the model estimates.

The paper finally illustrates the problems encountered and discusses future perspectives of the work.

\section{Study areas}

Italy is geographically situated between $36^{\circ}$ and $47^{\circ} 30^{\prime}$ ' North latitude and between $5^{\circ} 30^{\prime}$ and $18^{\circ} 30^{\prime}$ East longitude. Its orography is irregular and characterised by the presence of two main mountain chains, the Alps in the north and the Apennines in the centre-south. The climate is variable following the latitudinal and altitudinal gradients and the distance from the sea: in general, it ranges from Mediterranean Warm to Temperate Cool (Blasi 2005). Following the above gradients, also the land cover is changing, ranging from agricultural areas to forests and pastures.

As regards Mediterranean macchia (Fig. 1), this is spread all over Italy especially in the centre and in the south. Its presence is linked to particular ecological conditions (e.g., rocky soils, warm climate) and/or past utili- 


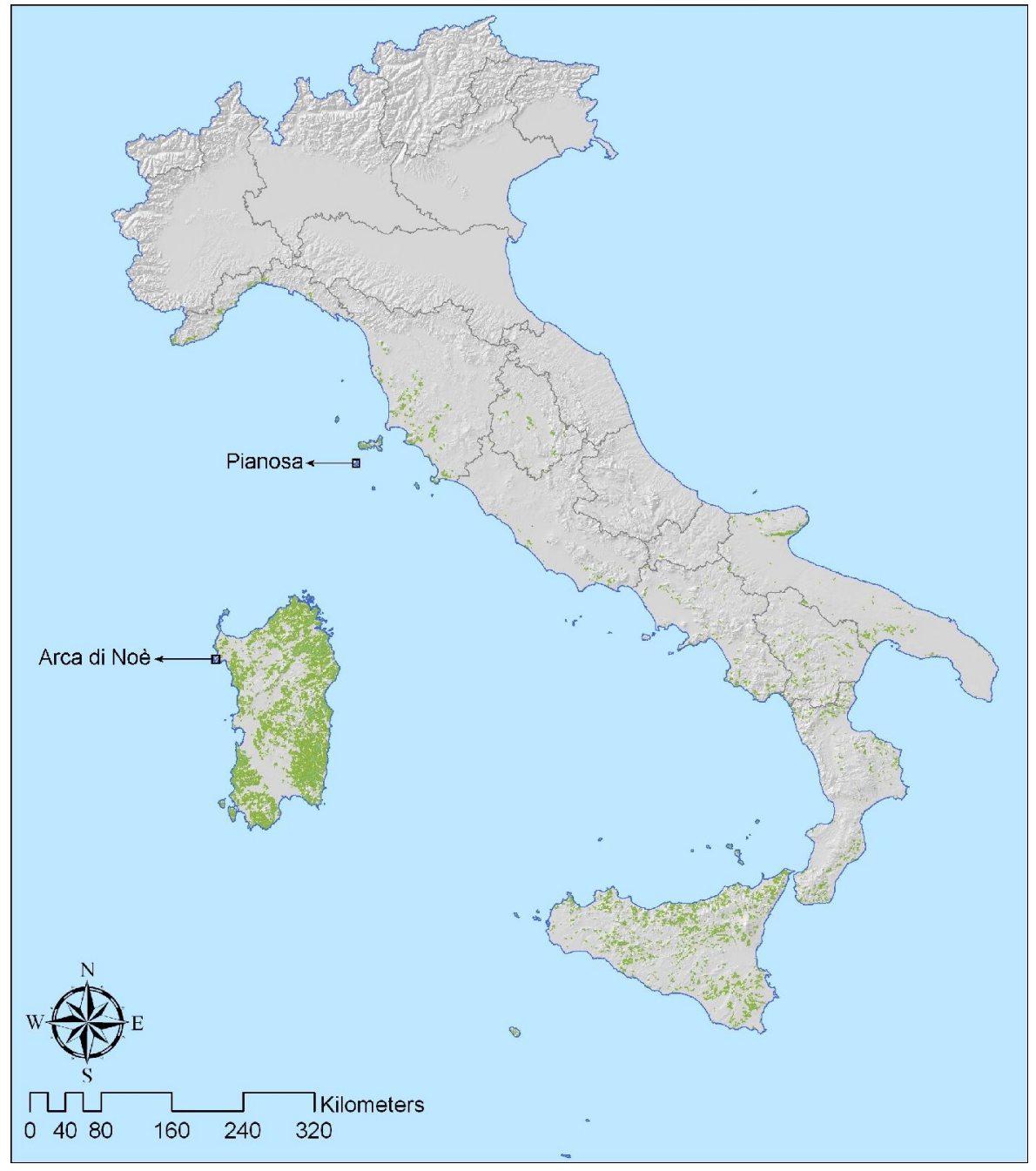

Fig. 1 - Distribution of shrub ecosystems dominated by sclerophyllous vegetation (class 323 from Corine Land Cover 2006) all over Italy, with indication of the two areas used for the validation (Arca di Noè and Pianosa).

zation (e.g., abandoned fields, forest fires). Following the CORINE Land Cover map from the European Environmental Agency at the year 2006, the shrub ecosystems dominated by sclerophyllous vegetation (class 323) cover approximately $10000 \mathrm{~km}^{2}$ (ISPRA 2010). According to FAO (2010), macchia is the most extended type of Other Wooded Land, which covers $17083 \mathrm{~km}^{2}$ against a forest area of $87592 \mathrm{~km}^{2}$ (INFC 2007).

Two specific sites, for which ET and GPP reference data are available, have been used to test the accuracy of the calibrated version of BIOME-BGC. The first test site is located inside a natural reserve called "Le Prigionette", also known as "Arca di Noè" $\left(40.6^{\circ} \mathrm{N}\right.$ lat., $8.15^{\circ} \mathrm{E}$ long., $28 \mathrm{~m}$ a.s.1.), an area situated in the north-western portion of the Sardinia island. Long-term weather records indicate that annual mean temperature is $15.9^{\circ} \mathrm{C}$, mean minimum temperature is $7{ }^{\circ} \mathrm{C}$, and mean maximum temperature is $28{ }^{\circ} \mathrm{C}$. Precipitation is mainly concentrated in spring and the mean total annual amount is $588 \mathrm{~mm}$. During autumn, there are often intense rainstorms with high runoff and low water storage (Marras et al. 2011). The soil is $0.3-0.4 \mathrm{~m}$ deep Lithic Xerorthent, which is mainly composed of clay with high erodibility. The prevalent species of this site are $J u$ niperus phoenicea L. (53\%), Pistacia lentiscus L. (22\%), and Phyllirea angustifolia L. (6\% - see http://fluxnet.ornl.gov). The species form a sparsely vegetated shrub land and they are aggregated into variable sized patches. The vegetation is a secondary succession following a fire event in 1963 and agricultural abandonment in 1970. Currently, the area has limited human activity. The mean vegetation height ranges from 0.9 to $1.8 \mathrm{~m}$. Ground cover varies between $45 \%$ and $95 \%$ (Marras et al. 2011).

The second test site $\left(42.58^{\circ} \mathrm{N}\right.$ lat., $10.05^{\circ}$ E long.) corresponds to a Mediterranean macchia placed on the Pianosa Island (Fig. 1). Based on data collected during the years
1951-2009, the average yearly temperature is $15.8^{\circ} \mathrm{C}$ and the mean annual rainfall is 497 $\mathrm{mm}$, mainly distributed from October to December (Vaccari et al. 2012). The thin soil layer of Pianosa is a Leptosols (ISSS/ISRIC/FAO 1998), sandy to loamy sandy, alkaline and rich of carbonate (Baraldi et al. 2004). Most of the island surfaces have been long used for agricultural activities, which ceased about 20 years ago. These areas are now being reinvaded by Mediterranean macchia, which is interspersed with abandoned fields and pastures and with small patches of other tree species (D'Acqui et al. 2007). The prevalent species of the macchia is Juniperus phoenicea L. (50-75\%); other species are Rosmarinus officinalis L., Bromus fasciculatus Presl., Pistacia lentiscus L. (50-25\% Colom et al. 2004).

\section{Study data}

\section{Ancillary data}

A Digital Elevation Model (DEM) of Italy with a pixel size of $1 \mathrm{~km}^{2}$ was used. This DEM was projected in the UTM-32 North reference system, which was taken as standard for processing all other information layers.

Daily meteorological data to run the model BIOME-BGC for the years 1999-2008 were derived by the E-OBS dataset (version 4.0), a high resolution gridded dataset funded by the EU-FP6 (Haylock et al. 2008 - see http://E-OBS-eu.metoffice.com). These data were originally provided at $0.25^{\circ}$ spatial resolution and then downscaled to $1 \mathrm{~km}$ by applying a locally calibrated regression procedure to the mentioned DEM (Maselli et al. 2012). Their accuracy was evaluated by comparison with data measured by ten ground meteorological stations spread over the Italian territory (see Maselli et al. 2012): a general overestimation of minimum temperatures and underestimation of rainfall was observed. These patterns, however, have little influence on the application of BIOME-BGC, which is mainly driven by maximum temperature; as regards precipitation, it mainly affects areas with high summer water stress.

Finally, a digital map of Mediterranean macchia was derived from the original CORINE Land Cover 2006 map of Italy (ISPRA 2010). This map was produced by manual photointerpretation of Landsat imagery supported by ancillary information. Also in this case the original map was rasterized at $1 \mathrm{~km}$ spatial resolution (Fig. 1).

\section{Monthly maps of GPP}

The reference data of GPP utilized to calibrate BIOME-BGC were produced using the modified C-Fix model, which is fully described in Maselli et al. (2009). The accuracy of this Monteith type model had already 
been evaluated by comparison with ground data of GPP obtained from numerous Italian eddy covariance flux towers (Maselli et al. 2009). These reference monthly maps covered all Italian forests and were available for the years 1999-2008 at $1 \mathrm{~km}$ spatial resolution.

\section{Macchia reference data}

In Italy there are three sites covered by Mediterranean macchia for which data of water and carbon fluxes are available: Tolfa $\left(42.18^{\circ} \mathrm{N}\right.$ lat., $11.93^{\circ} \mathrm{E}$ long.), Arca di Noè and Pianosa Island. The data of Tolfa were collected in a former study on the effect of water stress on plants (Alberti et al. 2007), and were excluded from the current analysis because the site was irrigated or artificially dried.

Reference evapotranspiration and photosynthesis values of the other two sites were derived from the existing towers measuring carbon fluxes by the eddy correlation technique. The daily ET and GPP values are available for different periods (2004-2008 for Arca di Noè and 2007-2008 for Pianosa Island). Both for Arca di Noè and Pianosa Island, mean annual ET is about $530 \mathrm{~mm} \mathrm{y}^{-1}$ and GPP is about $1100 \mathrm{~g} \mathrm{C} \mathrm{m}^{-2} \mathrm{y}^{-1}$. Further information on these sites can be found online at http://fluxnet.ornl.gov.

\section{Methods}

\section{The model BIOME-BGC}

BIOME-BGC is a bio-geochemical model developed at the University of Montana, which is freely distributed on the web. It can estimate the storage and fluxes of water, carbon and nitrogen within terrestrial ecosystems (Running \& Hunt 1993). It requires daily climate data (minimum and maximum temperature, precipitation and solar radiation), information on the general environment (i.e., soil depth and texture, vegetation

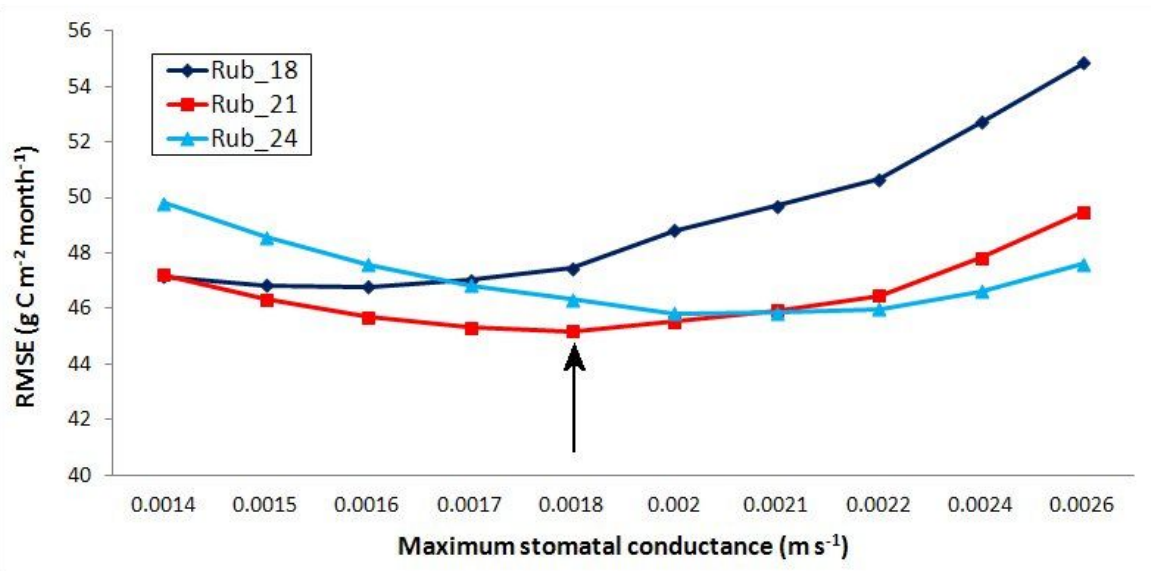

Fig. 2 - RMSEs obtained comparing GPP values derived from modified C-Fix and BIOMEBGC. These errors refer to different settings of the model which correspond to variable maximum stomatal conductances at different levels of the fraction of leaf nitrogen in Rubisco $(0.018,0.021$ and 0.024$)$.
Tab. 1 - Position and altitude of the ten selected points characterized by macchia cover

\begin{tabular}{cccc}
\hline ID & $\begin{array}{c}\text { Latitude } \\
\left({ }^{\circ} \mathbf{N}\right)\end{array}$ & $\begin{array}{c}\text { Longitude } \\
\left({ }^{\circ} \mathbf{E}\right)\end{array}$ & $\begin{array}{c}\text { Altitude } \\
(\mathbf{m} \text { asl })\end{array}$ \\
\hline 1 & 43.25 & 10.82 & 342 \\
2 & 42.90 & 11.13 & 166 \\
3 & 41.78 & 14.16 & 1185 \\
4 & 40.25 & 16.27 & 281 \\
5 & 38.10 & 15.75 & 885 \\
6 & 38.20 & 15.53 & 243 \\
7 & 38.15 & 13.13 & 454 \\
8 & 37.46 & 13.44 & 265 \\
9 & 40.87 & 9.57 & 114 \\
10 & 39.91 & 9.63 & 304 \\
\hline
\end{tabular}

and site conditions) and parameters describing the ecophysiological characteristics of the biome type considered. BIOME-BGC is capable of finding a quasi-climax equilibrium with local eco-climatic conditions through the spin-up phase, whose aim is to nitrogen pools; after that, it simulates all respiration and allocation processes corresponding to the requested simulation years (White et al. 2000, Churkina et al. 2003).

The version of the model currently used (ver. 4.2) includes complete parameter settings for different groups of biomes (i.e., evergreen neddleleaf, evergreen broadleaf, deciduous broadleaf, shrub, C3 and C4 White et al. 2000). These settings, however, must be modified to adapt to specific ecosystems, particularly in Mediterranean environments, which have eco-climatic features markedly different from those for which the model was originally developed (Chiesi et al. 2007).

\section{Calibration of BIOME-BGC}

The calibration of BIOME-BGC was carquantify the initial amount of all carbon and ried out by adjusting its monthly GPP outputs to reproduce the relevant C-Fix GPP estimates used as reference data (see also Chiesi et al. 2007). To this aim ten different sites characterised by the presence of macchia were selected using the 1-km CORINE Land Cover map of Italy. The criteria applied for this selection were geographic (points have to be at different altitudes and distributed in the centre-south of Italy - Tab. 1) and structural (the macchia fractional cover has to be close to $100 \%$ ). For each point, monthly GPP data were extracted from the available maps for the years 1999-2008 (10 plots x 10 years x 12 months), covering most relevant spatial and temporal (intra and inter-year) variability over the study region (Maselli et al. 2009).

BIOME-BGC was therefore applied to simulate the GPP behaviour of all study plots by using the available environmental and meteorological information. Among the BIOME-BGC initialization parameters, only those related to geographical position and terrain morphology were modified for each plot. Due to the lack of relevant information for all selected areas, parameters related to soil features were kept equal to medium conditions. All simulations were performed running the model in a "spin-up and go" mode, i.e., preliminarily finding an internal equilibrium of the model state variables (White et al. 2000). Concerning the eco-physiological parameter settings, the first trials were performed using the default biome type parameterization (i.e., shrub - White et al. 2000). According to Chiesi et al. (2007), the following trials were then carried out modifying the main parameters which regulate the resistance of forest species to summer drought (a typical Mediterranean feature) and altering the photosynthetic efficiency of macchia, with the modification of the leaf nitrogen content in Rubisco. The 1200 simulated monthly GPP values were regressed against the reference data obtained by C-Fix in order to find the lowest errors: these were considered indicative of the optimal reproduction of spatial and temporal GPP variations.

\section{Evaluation of BIOME-BGC perfor- mances}

The validation phase consisted of applying the calibrated BIOME-BGC model to the sites for which reference ET and GPP data were available (i.e., Arca di Noè and Pianosa).

The accuracy of model predictions are largely dependent on the quality of input data (Chiesi et al. 2011). In order to evaluate this quality, the 1-km downscaled daily meteorological data used for model initialization were tested against available measurements for the two validation sites. To this aim, the daily temperature and precipitation collected during the periods covered by ET 
and GPP data (i.e., 2004-2008 for Arca di Noè and 2007-2008 for Pianosa Island) were compared to the available daily estimates by conventional accuracy statistics (correlation coefficient: $r$; root mean square error: RMSE; and mean bias error: MBE). Only daily average temperature was available for Arca di Noè while for Pianosa Island both minimum and maximum temperatures were used; rainfall data were available for both sites.

After the data quality assessment described above, the downscaled daily meteorological data were utilised to preliminarily drive the algorithm MT-Clim (Thornton et al. 2000) and compute solar radiation. The model BIOME-BGC was then applied for each site and the goodness-of-fit of its outputs onto ET and GPP reference data was evaluated by means of the same accuracy statistics as above ( $r$, RMSE and MBE). The simulation accuracy at various temporal scales was assessed by computing the above statistics from data aggregated on daily, weekly and monthly basis.

\section{Results}

\section{Calibration phase}

The results obtained comparing reference and estimated GPP are shown in Fig. 2. The lowest root mean square error (indicated by the arrow therein) corresponds to a maximum stomatal conductance of $0.0018 \mathrm{~m} \mathrm{~s}^{-1}$.

As regards the fraction of leaf nitrogen contained in Rubisco, the best results are obtained when it is set to 0.021 .

\section{Accuracy assessment}

The comparison between downscaled meteorological data and the data measured by the flux tower for Arca di Noè indicates that the former provides good estimates of average temperature $(r=0.944, \mathrm{RMSE}=2.05$ ${ }^{\circ} \mathrm{C}$ and $\mathrm{MBE}=0.44{ }^{\circ} \mathrm{C}$ ) with an underestimation of precipitation (total amount during the study period of 2486 against $2524 \mathrm{~mm}$ ). In addition, the number of rainy days is not correctly identified.

Fig. 3 shows the daily trend of reference GPP compared with the simulated estimates obtained from the modified settings. In general, GPP reference data reach a maximum in late spring while during summer the vegetation activity is reduced. A similar trend is found for the simulated GPP estimates, though a shift between the peaks of the two profiles is often observed, strictly depending on the years (i.e., it is more evident in 2004).

The results of the comparison between eddy flux tower data and BIOME-BGC estimates are shown in Tab. $2 \mathrm{a}$ and Tab. $2 \mathrm{~b}$ for ET and GPP, repectively. These results are obtained using both the original and the modified settings of BIOME-BGC. The simulation of ET leads to errors of about 1.5

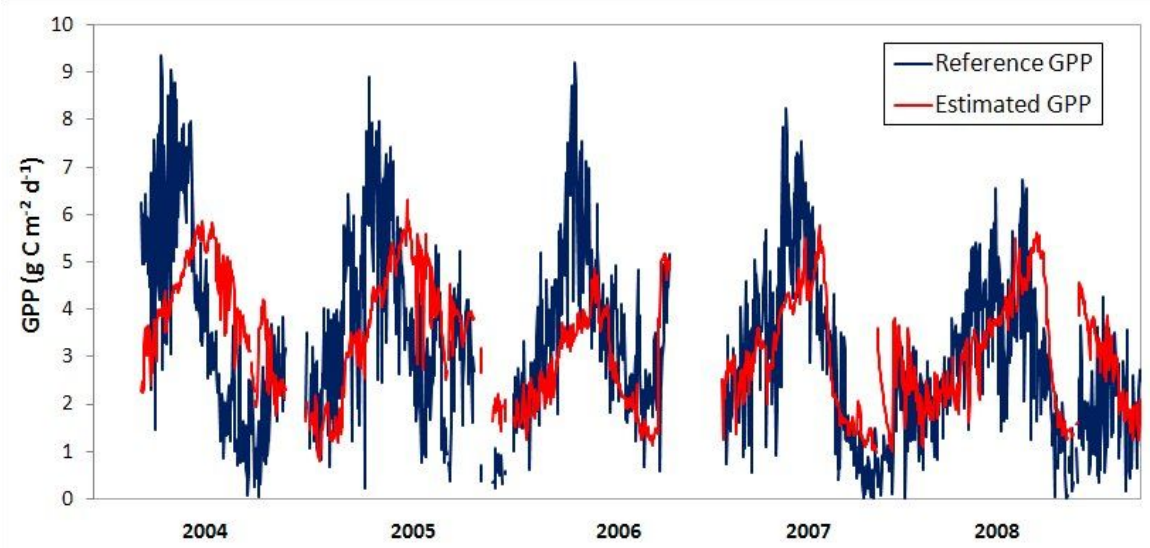

Fig. 3 - Reference and estimated daily GPP values at Arca di Noè test site for the period 2004-2008

Tab. 2 - Statistics referred to evapotranspiration (a) and GPP (b) values computed on yearly, monthly and weekly basis for Arca di Noè site. The errors for ET are expressed in mm day ${ }^{-1}$ $\mathrm{mm}$ week ${ }^{-1}$ and $\mathrm{mm}$ month $^{-1}$, those for GPP are in $\mathrm{g} \mathrm{C} \mathrm{m}^{-2}$ day $^{-1}, \mathrm{~g} \mathrm{C} \mathrm{m}^{-2}$ week ${ }^{-1}$ and $\mathrm{g} \mathrm{C} \mathrm{m}^{-2}$ month $^{-1}$, respectively. $(r)$ : correlation coefficient; (RMSE): root mean square error; (MBE): mean bias error. All correlation coefficients are highly significant with $\mathrm{P}<0.01$.

\begin{tabular}{llrrrrrr}
\hline \multirow{2}{*}{ Parameter } & \multirow{2}{*}{ Time } & \multicolumn{3}{c}{ Original settings } & \multicolumn{3}{c}{ Modified settings } \\
\cline { 3 - 8 } & & \multicolumn{1}{c}{$\boldsymbol{r}$} & RMSE & MBE & \multicolumn{1}{c}{$\boldsymbol{\text { RMSE }}$} & \multicolumn{1}{c}{ MBE } \\
\hline (a) Evapo- & Daily & 0.347 & 1.67 & -0.05 & 0.292 & 1.55 & -0.06 \\
transpiration & Weekly & 0.556 & 6.94 & 0.26 & 0.502 & 5.75 & 0.28 \\
& Monthly & 0.607 & 22.05 & 1.35 & 0.554 & 17.59 & 1.27 \\
\hline (b) GPP & Daily & 0.508 & 1.65 & 0.96 & 0.501 & 1.61 & -0.02 \\
& Weekly & 0.548 & 10.72 & 1.58 & 0.571 & 10.22 & 0.57 \\
& Monthly & 0.619 & 38.24 & 5.03 & 0.607 & 38.56 & 0.46 \\
\hline
\end{tabular}

$\mathrm{mm}$ day $^{-1}$ and rather low correlation coefficients $(0.347$ and 0.297 with the original and the modified settings, respectively). When the data are aggregated on weekly and monthly basis, $r$ notably increases, reaching the maximum value of 0.607 for the original settings.

The RMSEs are generally lower when the calibrated version is applied, while the MBEs are more or less stable. The same trends are observed for the simulation of GPP, though in this case the errors obtained with the modified settings are generally

lower than those with the original ones (Tab. 2b)

For Pianosa Island, the downscaled daily meteorological dataset provides accurate estimates of maximum temperature (annual average of $22.4^{\circ} \mathrm{C}$ vs. $22.8^{\circ} \mathrm{C} ; r=0.962$, RMSE $=2.18{ }^{\circ} \mathrm{C}$ and $\mathrm{MBE}=0.46{ }^{\circ} \mathrm{C}$ ), while it underestimates minimum temperature $\left(11.8{ }^{\circ} \mathrm{C} v s .15 .0^{\circ} \mathrm{C} ; r=0.85\right.$, RMSE $=$ $4.65{ }^{\circ} \mathrm{C}$ and $\left.\mathrm{MBE}=-3.22{ }^{\circ} \mathrm{C}\right)$. Concerning annual rainfall, the total amount is well estimated (annual estimate of $291 \mathrm{~mm} v \mathrm{~s}$. $281 \mathrm{~mm}$ measured); also in this case the

Tab. 3 - Statistics referred to evapotranspiration (a) and GPP (b) data computed on yearly, monthly and weekly basis for Pianosa Island. The errors for ET are expressed in $\mathrm{mm} \mathrm{day}^{-1}$, $\mathrm{mm}$ week ${ }^{-1}$ and $\mathrm{mm} \mathrm{month}{ }^{-1}$, those for GPP are in $\mathrm{g} \mathrm{C} \mathrm{m}^{-2}$ day $^{-1}, \mathrm{~g} \mathrm{C} \mathrm{m}^{-2}$ week ${ }^{-1}$ and $\mathrm{g} \mathrm{C} \mathrm{m}^{-2}$ month $^{-1}$, respectively. $(r)$ : correlation coefficient; (RMSE): root mean square error; (MBE): mean bias error. All correlation coefficients are highly significant with $\mathrm{P}<0.01$.

\begin{tabular}{llrrrrrr}
\hline \multirow{2}{*}{ Parameter } & \multirow{2}{*}{ Time } & \multicolumn{3}{c}{ Original settings } & \multicolumn{3}{c}{ Modified settings } \\
\cline { 3 - 8 } & & \multicolumn{1}{c}{$\boldsymbol{r}$} & RMSE & \multicolumn{1}{c}{ MBE } & \multicolumn{1}{c}{$\boldsymbol{r}$} & RMSE & \multicolumn{1}{c}{ MBE } \\
\hline (a) Evapo- & Daily & 0.217 & 1.79 & -0.13 & 0.297 & 1.66 & -0.06 \\
transpiration & Weekly & 0.261 & 8.73 & 0.57 & 0.415 & 7.39 & 0.98 \\
& Monthly & 0.398 & 24.83 & 1.61 & 0.576 & 21.56 & 3.90 \\
\hline (b) GPP & Daily & 0.271 & 2.04 & 0.37 & 0.548 & 1.64 & 0.29 \\
& Weekly & 0.203 & 13.21 & 2.38 & 0.644 & 9.67 & -2.71 \\
& Monthly & 0.294 & 46.94 & -10.79 & 0.733 & 34.05 & 11.89 \\
\hline
\end{tabular}




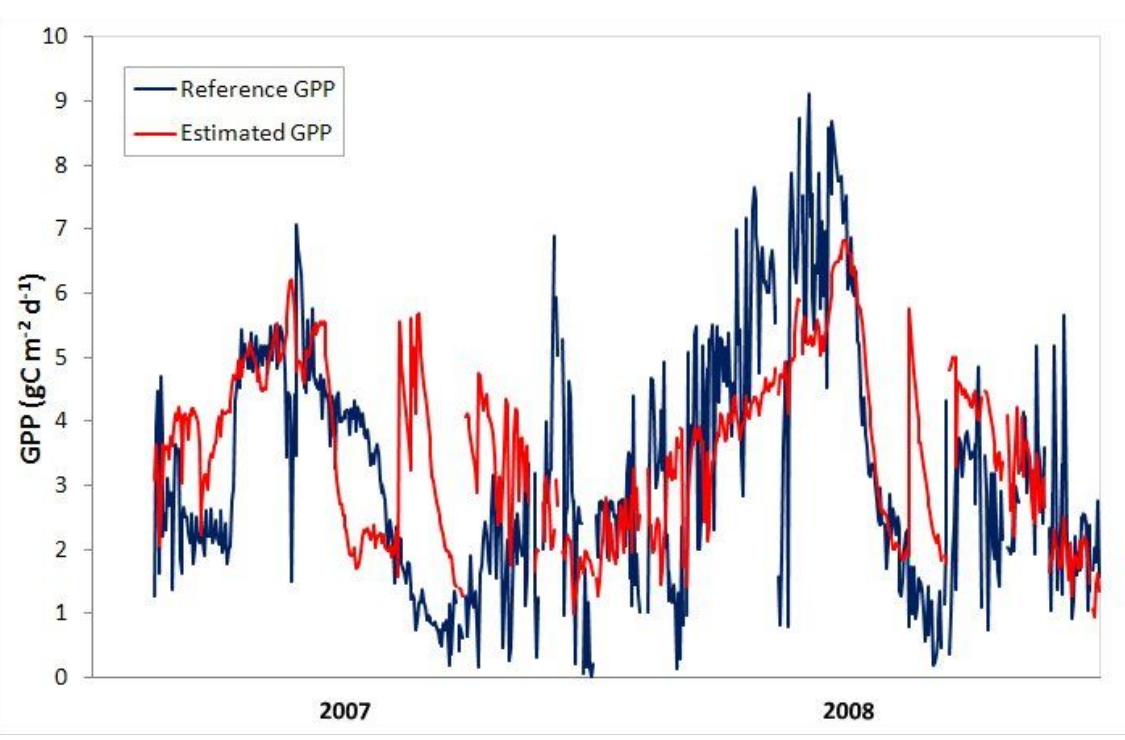

Fig. 4 - Reference and estimated daily GPP values at Pianosa Island for the period 20072008.

number of rainy days is not correctly estimated.

The daily values of measured and simulated GPP are shown in Fig. 4 for 2007 and 2008. The accuracy of model predictions is fairly satisfactory and the total annual amounts are very similar for the two dataset $\left(r=0.548\right.$, RMSE $=1.64 \mathrm{~g} \mathrm{C} \mathrm{m}^{-2}$ day $^{-1}$ and $\left.\mathrm{MBE}=0.29 \mathrm{~g} \mathrm{C} \mathrm{m}^{-2} \mathrm{day}^{-1}\right)$. As shown by the same figure, the annual vegetation cycle is not accurately simulated by the model considered, thus some peaks of measured GPP are not reproduced by the model and vice versa.

The accuracy of the simulations obtained for ET and GPP by BIOME-BGC is reported in Tab. 3. In general, the correlation coefficients found using the original model settings are much lower than those found for the calibrated ones, for both the parameters considered. A better fitting is observed for the simulation of GPP than for ET. Also in this case, a remarkable increase in the accuracy of model predictions is observed considering different data aggregations (from daily to monthly), indicating that the general trend is captured by the model.

\section{Discussion and conclusions}

BIOME-BGC is a powerful model of terrestrial ecosystem processes which requires an accurate calibration for each biome type and abundant information on the areas examined (Running \& Hunt 1993). The calibration phase applied in this work utilizes as reference data the monthly maps of GPP obtained by Maselli et al. (2009) for the years 1999-2008. The reliability of these maps was assessed through comparison with monthly measurements of GPP collected by the eddycovariance technique over eight Italian test sites; in general, the modified version of CFix is particularly suited for Mediterranean forest areas with more pronounced drought period. A different study evaluated the accuracy of the daily meteorological dataset which was needed to characterise the whole national territory and initialize the model (Maselli et al. 2012).

This calibration phase brought to identify the parameter settings for BIOME-BGC. These settings cannot be directly compared to those of other macchia sites, due to the lack of similar previous studies on this ecosystem type. Both the maximum stomatal conductance and the fraction of leaf nitrogen in Rubisco identified, however, are slightly lower than those found for similar evergreen species (e.g., Schulze et al. 1994, Mollicone et al. 2003).

Reference ET and GPP values collected by the eddy-correlation technique were used for testing the performances of the calibrated model versus its original version with parameter settings for shrubs. The analysis of the results should take into account that the eddy covariance data used for the test might be affected by uncertainties due to the gap-filling and partitioning algorithms applied (Papale et al. 2006). Additionally, the reference data are not continuous during the investigated periods, suggesting difficulties in their collection for both sites (see also Chiesi et al. 2011). In order to reduce the possible effects of the above problems on our investigation, the simulation accuracy was assessed on data aggregated on daily, weekly and monthly basis. The results obtained indicate that the calibration procedure has improved the model capacity to reproduce both ET and GPP of Mediterranean macchia. Generally, the accuracy obtained for ET is lower than that obtained for GPP. This discrepancy may stem from problems in correctly reproducing the daily precipitation data compared to temperatures and, in particular, in identifying rainy days and estimating the total amount of precipitation per day.

The Arca di Noè site has a long time series of data, which allows to test the applicability of BIOME-BGC in years with different meteorological conditions. As shown in Fig. 3, the annual trend of variation for the parameters considered is fairly well reproduced, though a shift in the simulation of the GPP peaks was observed, especially at the beginning of the year (e.g., see 2004). This may be partly due to the errors which affect the used meteorological dataset.

The Pianosa study site is placed on a flat island which is being reinvaded by heterogeneous Mediterranean macchia. This condition is optimal to correctly apply the eddy covariance technique, but it is suboptimal to apply BIOME-BGC, which is suited to simulate the behaviour of spatially homogeneous ecosystems (Running \& Hunt 1993).

For both sites the accuracy of predictions for ET and GPP is improved with respect to that found for similar vegetation types in other studies (e.g., Chiesi et al. 2011). As regards the Pianosa Island, Chiesi et al. (2011) obtained a correlation coefficient of 0.599 and an error of $67.43 \mathrm{~g} \mathrm{C} \mathrm{m}^{-2}$ month $^{-1}$. The differences found between these and the current results current results $(r=0.733$, RMSE $=34.05 \mathrm{~g} \mathrm{C} \mathrm{m}^{-2}$ month $^{-1}$ ) are partly due to the daily meteorological data used as input, which are now more accurate, and to the different calibration of the model, which is currently obtained starting from the shrub biome-type in place of evergreen broadleaf forest.

Globally, the results obtained indicate that a properly calibrated version of BIOME-BGC can be adopted to predict both water and carbon fluxes of Mediterranean macchia on a monthly basis. This newly parameterized biome-type can contribute to describe the behaviour of Italian forest ecosystems in sight of monitoring and quantifying changes in forest production over years.

\section{Acknowledgments}

The work was carried out under the C_FORSAT project "Modelling the carbon sink in Italian forest ecosystems using ancillary data, remote sensing data and productivity models" (national coordinator: Prof. G. Chirici) funded by the FIRB2008 program of the Italian Ministry of Education, University and Research (code: RBFR08LM04). The authors wish to thank two anonymous reviewers and the subject editor of iForest, Prof. R. Tognetti, whose comments contributed to improve the first draft of the manuscript. 


\section{References}

Alberti G, Inglima I, Arriga N, Piermatteo D, Pecchiari M, Zaldei A, Papale D, Peressotti A, Valentini R, Cotrufo MF, Magnani F, Miglietta F (2007). Cambiamenti nel regime pluviometrico in ecosistemi mediterranei: il progetto MIND. Forest@ 4 (4): 460-468. - doi: 10.3832/ efor0493-0040460

Baraldi R, Vaccari FP, Colom MR, Cotrufo MF, D'Acqui LP (2004). The Pianosa_LAB: an integrated research project to assess the carbon balance of Pianosa island. Journal of Mediterranean Ecology 5: 5-13. [online] URL: http://www.jmecology.com/pdf/2004/2.BARALDI_R.pdf

Blasi C (2005). Spazializzazione di variabili climatiche su base nazionale. Manuscript. Ministero dell'Ambiente e del Territorio, Roma, Italy. Chiesi M, Maselli F, Moriondo M, Fibbi L, Bindi M, Running SW (2007). Application of BIOME$\mathrm{BGC}$ to simulate Mediterranean forest processes. Ecological Modelling 206 (1-2): 179-190. - doi: 10.1016/j.ecolmodel.2007.03.032

Chiesi M, Moriondo M, Maselli F, Gardin L, Fibbi L, Bindi M, Running SW (2010). Simulation of Mediterranean forest carbon pools under expected environmental scenarios. Canadian Journal of Forest Research 40 (5): 850-860. doi: 10.1139/X10-037

Chiesi M, Fibbi L, Genesio L, Gioli B, Magno R, Maselli F, Moriondo M, Vaccari F (2011). Integration of ground and satellite data to model Mediterranean forest processes. International Journal of Applied Earth Observation and Geoinformation 13 (3): 504-515. - doi: 10.1016/j.jag. 2010.10.006

Churkina G, Tenhunen J, Thornton P, Falge EM, Elbers JA, Erhard M, Grunwald T, Kowalski AS, Rannik U, Sprinz D (2003). Analyzing the ecosystem carbon dynamics of four European coniferous forests using a biogeochemistry model. Ecosystems 6 (2): 168-184. - doi: 10.1007/ s10021-002-0197-2

Colom MR, Vaccari FP, Scartazza A, Brugnoli E, Zerbi G, Sforzi S, Baraldi R, Cotrufo MF, D'Acqui L, Santi C, Vazzana C, Vivoli R, Spaccino L (2004). Pianosa island: structure, functioning and biodiversity of main ecosystems. Journal of Mediterranean Ecology 5 (1): 31-40. [online] URL: http://pages.unibas.ch/geo/mcr/Projects/PIANOSA/History/Articles/pianosa_LAB_Colom. pdf

Corona P (2010). Integration of forest mapping and inventory to support forest management. iForest - Biogeosciences and Forestry 3 (1): 59 64. - doi: 10.3832/ifor0531-003

Cramer W, Kicklighter DW, Bondeau A, Iii BM, Churkina G, Nemry B, Ruimy A, Schloss AL, Intercomparison TP (1999). Comparing global models of terrestrial net primary productivity (NPP): overview and key results. Global Change Biology 5 (S1): 1-15. - doi: 10.1046/j.1365- 2486.1999.00009.x

D'Acqui LP, Santi CA, Maselli F (2007). Use of ecosystem information to improve soil organic carbon mapping in a Mediterranean island. Journal of Environment Quality 36: 262-271. doi: $10.2134 /$ jeq 2005.0283

FAO (2010). Global forest resources assessment. Food and Agriculture Organization of the United Nations, Rome, Italy, pp. 375.

Haylock MR, Hofstra N, Klein Tank AM, Klok EJ, Jones PD, New M (2008). A European daily high-resolution gridded data set of surface temperature and precipitation for 1950-2006. Journal of Geophysical Research 113 (D20). - doi: 10.1029/2008JD01020

INFC (2007). Le stime di superficie 2005 - Prima parte. Inventario Nazionale delle Foreste e dei Serbatoi Forestali di Carbonio. MiPAF - Corpo Forestale dello Stato - Ispettorato Generale, CRA - ISAFA, Trento. [online] URL: http://www.infc.it

IPCC (2007). Climate change 2007: impacts, adaptation and vulnerability. IPCC Forth Assessment Report (Parry ML, Canziani OF, Palutikof JP, van der Linden PJ, Hanson CE eds). Cambridge University Press, Cambridge, UK, pp. 976. [online] URL: http://www. ipcc.ch/

ISPRA (2010). La realizzazione in Italia del Progetto Corine Land Cover 2006. Istituto Superiore per la Protezione e la Ricerca Ambientale, Rome, Italy, pp. 50.

ISSS/ISRIC/FAO (1998). World reference base for soil resources. Acco Press, Leuven, Belgium, pp. 79

Marras S, Pyles RD, Sirca C, Paw U KT, Snyder RL, Duce P, Spano D (2011). Evaluation of the Advanced Canopy-Atmosphere-Soil Algorithm (ACASA) model performance over Mediterranean maquis ecosystem. Agricultural and Forest Meteorology 151: 730-745.

Maselli F, Papale D, Puletti N, Chirici G, Corona $P$ (2009). Combining remote sensing and ancillary data to monitor the gross productivity of water-limited forest ecosystems. Remote Sensing of Environment 113 (3): 657-667. - doi: 10.1016/ j.rse.2008.11.008

Maselli F, Pasqui M, Chirici G, Chiesi M, Fibbi L, Salvati R, Corona P (2012). Evaluation of a 1$\mathrm{km}$ daily meteorological dataset for modelling vegetation production in Italy. Climate Research (under revision).

Matsushita B, Tamura M (2002). Integrating remotely sensed data with an ecosystem model to estimate net primary productivity in East Asia. Remote Sensing of Environment 81 (1): 58-66. doi: 10.1016/S0034-4257(01)00331-5

Mollicone D, Matteucci G, Köble R, Masci A, Chiesi M, Smits PC (2003). A model-based approach for the estimation of carbon sinks in European forests. In: "Fluxes of carbon, water and energy in European forests" (Valentini R ed). Springer-Verlag, Berlin, Germany, pp. 297. Papale D, Reichstein M, Aubinet M, Canfora E, Bernhofer C, Kutsch W, Longdoz B, Rambal S, Valentini R, Vesala T, Yakir D (2006). Towards a standardized processing of Net Ecosystem Exchange measured with eddy covariance technique: algorithms and uncertainty estimation. Biogeosciences 3 (4): 571-583. - doi: 10.5194/ bg-3-571-2006

Running SW, Hunt ER (1993). Generalization of a forest ecosystem process model for other biomes, BIOME-BGC, and an application for global-scale models. In: "Scaling physiological processes: leaf to globe" (Ehleringer JR, Field CB eds). Academic Press, San Diego, USA, pp. 141158. [online] URL: http://secure.ntsg.umt.edu/ publications/1993/RH93/Running_CH8_Scaling PhysProcesses.pdf

Schulze E-D, Kelliher FM, Korner C, Lloyd J, Leuning R (1994). Relationships among maximum stomatal conductance, ecosystem surface conductance, carbon assimilation rata and plant nitrogen nutrition: a global ecology scaling exercise. Annual Reviews of Ecological Systems 25: 629-662.

Thornton PE, Hasenauer H, White MA (2000). Simultaneous estimation of daily solar radiation and humidity from observed temperature and precipitation: an application over complex terrain in Austria. Agricultural and Forest Meteorology 104 (4): 255-271. - doi: 10.1016/S01681923(00)00170-2

Vaccari FP, Lugato E, Gioli B, D'Acqui L, Genesio L, Toscano P, Matese A, Miglietta F (2012). Land use change and soil organic carbon dynamics in Mediterranean agro-ecosystems: The case study of Pianosa Island. Geoderma 175176: 29-36.

Veroustraete F, Sabbe H, Eerens H (2002). Estimation of carbon mass fluxes over Europe using the C-Fix model and Euroflux data. Remote Sensing of Environment 83 (3): 376-399. - doi: 10.1016/S0034-4257(02)00043-3

Waring HR, Running SW (2007). Forest ecosystems. Analysis at multiples scales ( $3^{\text {rd }}$ edn). Academic Press, San Diego, USA.

White MA, Thornton PE, Running SW, Nemani RR (2000). Parameterization and sensitivity analysis of the BIOME-BGC terrestrial ecosystem model: net primary production controls. Earth Interactions 4 (3): 1-85. - doi: 10.1175/1087-3562 (2000)004<0003:PASAOT $>2.0 . C O ; 2$

Yang F, Ichii K, White MA, Hashimoto H, Michaelis AR, Votava P, Zhu AX, Huete A, Running SW, Nemani RR (2007). Developing a continental-scale measure of gross primary production by combining MODIS and AmeriFlux data through Support Vector Machine approach. Remote Sensing of Environment 110 (1): 109-122. - doi: 10.1016/j.rse.2007.02.016 